\title{
EDITORIAL
}

\section{Need to Broad-Base Higher Education}

Syed Muhammad Imran Majeed, Rehma Ahsan Gilani

"All religions, arts, and sciences are branches from the same tree." Albert Einstein

Establishment of human intellect and expertise necessitates wide scope of knowledge and understanding. Post qualification, many practical jobs wherein the required expertise includes social understanding and abilities which are not included in STEM subjects. Organization needs civic sense, team work, understanding, compassion and good communication. In reality, the market needs that the product of higher education being employed has these abilities so as to be able to get well within the organizational work forces.

A well-developed human package is hardly complete without appropriate knowledge and insight of, for example, philosophy, anthropology, economics, law, psychology, belief system/religions, geography, history and politics, amongst others. Without these, the very purpose of one's role within an organization, and the society at large, remains very incomplete.

Obtaining passing marks in merely a few science specific subjects as usually defined in narrowly defined curricular stop way short of meeting the market demands. Inclusion of some knowledge of social sciences, humanities and arts would help create higher educated people with better understanding of the human condition and the society. Better understanding is the essential prerequisite for being comfortable with oneself and one's society.

On the same account, integrative education and research needs to be put in place to bridge knowledge, modes of inquiring and pedagogies from multiple disciplines, within every higher education program.

\section{Editor-in-Chief}

How to cite this: Majeed SMI, Gilani RA. Need to Broad-Base Higher Education. Life and Science. 2021; 2(2): 41-41. doi: http://doi.org/10.37185/LnS.1.1.200

This is an Open Access article distributed under the terms of the Creative Commons Attribution License (http://creativecommons.org/licenses/by/4.0), which permits unrestricted use, distribution, and reproduction in any medium, provided the original work is properly cited. 